\title{
Self-Reported Sleep Duration, Daytime Sleepiness, and Caffeine Use in Male and Female Morning and Evening Types
}

\author{
Seong Jae Kim, MD, $\mathrm{PhD}^{1}$, Jung Hie Lee, MD, $\mathrm{PhD}^{2,4}$, In Soo Kim, $\mathrm{MD}^{3}$, Kwang Ho Jang, $\mathrm{MD}^{2}$, Jeanne F. Duffy, $\mathrm{PhD}^{4}$ \\ 'Department of Neurology, Northwestern University Feinberg School of Medicine, Chicago, IL, USA \\ 2Department of Psychiatry, Kangwon National University Hospital, Chuncheon, Korea \\ ${ }^{3}$ Department of Psychiatry, Cheongju Medical Center, Cheongju, Korea \\ ${ }^{4}$ Division of Sleep Medicine, Brigham \& Women's Hospital, Harvard Medical School, Boston, MA, USA
}

\begin{abstract}
Background and Objective Previous studies in adults have focused on differences in sleep timing with respect to morning and evening (ME) types, or gender difference in the distribution of ME types. We aimed to examine sleep habits and behaviors (daytime sleepiness and caffeine consumption) of adult ME types, and to examine whether the factors associated with ME type differed between men and women.

Methods Among 1,086 subjects to whom we administered the Korean version of Horne-Ostberg Morningness-Eveningness Questionnaire (MEQ-K), the Korean version of the Epworth Sleepiness Scale (KESS), the Pittsburgh Sleep Quality Index (PSQI) and asked questions about their sleep-wake timing and caffeine use, the data from 911 subjects (age: $38.4 \pm 10.9$ years, range: 18-88; $F: M=565$ : 346) were analyzed. Standard scores of the MEQ were used to categorize the subjects as morning type (MT), evening type (ET) and neither type (NT).

Results In the overall group, results from the PSQI indicated a significantly shorter sleep duration and greater caffeine consumption in ET when compared to those of MT or NT ( $p<0.05)$. This was also found in the subgroup of women $(\mathrm{p}<0.01)$, but not in the subgroup of men. Daytime sleepiness as reported on the KESS was significantly greater in the ET than the NT or MT overall (p $<0.05)$ and among the women $(\mathrm{p}<0.01)$, but did not reach significance among men.

Conclusions Our study found that ET subjects perceived their sleep quality as poorer than that of MT or NT subjects regardless of gender. We also found that ET women had significantly shorter sleep duration, greater daytime sleepiness, and larger caffeine consumption than MT or NT women, but we did not find the same findings in the men.

Sleep Med Res 2012;3:32-38
\end{abstract}

Key Words Morning type, Evening type, Gender, Sleep duration, Daytime sleepiness, Caffeine use.

Received: February 9, 2013

Revised: April 15, 2013

Accepted: May 13, 2013

Correspondence

Jung Hie Lee, MD, PhD

Department of Psychiatry,

Kangwon National University Hospital,

156 Baengnyeong-ro,

Chuncheon 200-947, Korea

Tel $+82-33-258-2310$

Fax +82-33-256-3344

E-mail jhielee@kangwon.ac.kr

\section{INTRODUCTION}

Morningness-eveningness (ME) is defined as the diurnal preference, and it reflects individual differences in the preferred time of activity revealed by general behavioral patterns, including sleep timing. ${ }^{1}$ The temporal misalignment between endogenous circadian rhythms and the timing of the sleep-wake cycle has been hypothesized to have a negative influence on sleep. Such a mismatch is mainly found in evening type (ET) subjects, who prefer late bedtimes and wake times, and who in many cases have shortened sleep on weekdays because of the need to wake early for school or work. ${ }^{2-4}$ There are several reports that ET subjects have a shorter sleep duration on work days, ${ }^{2,4,5}$ and sleep duration becomes shorter as the work times move earlier. ${ }^{6}$ In addition to having shorter sleep on weeknights, ET individuals may have other characteristics such as irregular sleep habits and/or an excessive need for sleep that can impact their sleep quality in a negative way. ${ }^{4}$ In a previous study of factors that affect sleep quality, ${ }^{7}$ evening preference was a better predictor of poor sleep quality than job characteristics such as shift work or life pattern. Furthermore, these differences in sleep habits between ME types are associated with other behaviors that suggest ET individuals have a sleep deficit, including greater caffeine 
consumption and greater sleep extension on free days. ${ }^{4}$ Some of the sleep and behavior patterns typical of ME types may be influenced by occupational and environmental factors, and there is also a well-documented influence of age on morningness-eveningness. ${ }^{8,9}$ Adolescents have an increased tendency towards eveningness, with a population peak in eveningness around age $20 .{ }^{10}$ In contrast, older individuals tend towards morningness. It was reported that the peak eveningness of females occurs around age 19.5, earlier than that of males (who reach their peak eveningness at age 21 ), and this gender difference disappeared around the age of menopause. ${ }^{10}$ This gender difference in ME preference has been hypothesized to be due to female reproductive hormones. Recently, it was reported that the intrinsic circadian period of women is shorter than that of men, implying a gender difference in the biological features of the circadian system. ${ }^{11}$ Furthermore, several studies have reported a gender difference in behavior according to ME preference. One study reported that male ET subjects were associated with hyperactivity-impulsivity, ${ }^{12}$ and another that female ET subjects were associated with a decline of language function. ${ }^{13}$

Giannotti et al. ${ }^{2}$ reported that among adolescents, emotional problems, substance use such as caffeine, and daytime sleepiness were greater in the ET group than in the MT group. A gender difference in emotional problems, substance use, and sleep habits by ME type was also suggested. Despite this, few studies have been conducted on whether there is a gender difference in sleep habits and behaviors in adults with respect to the ME type. Previous studies in adults have focused on differences in sleep timing with respect to the ME type, or gender differences in the distribution of ME types. ${ }^{14-17}$ Therefore, in the present study we aimed to examine sleep habits and behaviors (daytime sleepiness and caffeine consumption) of adult ME types, and to examine whether those factors associated with the ME type differed between men and women.

\section{METHODS}

\section{Subjects}

We studied 1,086 adults (age 18 years or older), who visited the Chunchon National Museum or the Health Promotion Centers at Kangwon National University Hospital or Hyosung Hospital in Korea, between September 2009 and December 2010. After excluding subjects with a history of shift work, a current sleep disorder diagnosis, and those with missing data, data from 911 subjects (age: $38.4 \pm 10.9$ years, range: $18-88, \mathrm{~F}: \mathrm{M}=565: 346$ ) were available for analysis. The study was approved by the Institutional Review Board at Kangwon National University Hospital, and written informed consent was obtained from each participant after full explanation of the study procedure.

\section{Questionnaires}

The Korean Sleep-Wake Questionnaire (SWQ-K) was administered to each subject. This included Korean versions of the Morningness-Eveningness Questionnaire (MEQ-K), ${ }^{18}$ Epworth Sleepiness Scale (KESS), ${ }^{19}$ and Pittsburgh Sleep Quality Index (PSQI), ${ }^{20}$ and questions about sleep habits (such as self-assessed sleep need, sleep times on weekdays and weekends, and usual caffeine consumption).

Before using the SWQ-K, we examined the internal consistency of the MEQ-K and PSQI in 91 subjects and the test-retest reliability in 21 subjects. Cronbach's alpha for the MEQ-K was 0.77 , and the correlation coefficient between the MEQ-K scores for verifying the test-retest reliability was 0.898 ( $p<0.0001)$. For the PSQI, Cronbach's alpha for the global score was 0.74 and for each of the seven components, it was 0.84 , and the correlation coefficient between the PSQI scores for verifying the test-retest reliability was $0.792(\mathrm{p}<0.0001)$. The questionnaires of the subjects who took part in the internal consistency and test-retest reliability testing were included in our overall study population.

The standard scores of the MEQ proposed by Horne and Ostberg ${ }^{18}$ were used to categorize the subjects as morning type (MT), neither type (NT), or evening type (ET). Sleep habits, and bedtimes and wake times of individual subject were examined using responses from the PSQI. Among the seven components of the PSQI, the raw values for sleep latency and sleep duration were used rather than their component scores.

\section{Statistical Analysis}

Demographic variables and the scores of the MEQ-K, KESS and PSQI were compared by ANOVA or ANCOVA (controlling for age) between the male and female groups. The scores of the MEQ-K, KESS and PSQI were compared by ANCOVA controlling for age between the MT, NT and ET groups. The same analyses by ME type were also done in the male and female groups separately. The bedtime, wake time, sleep latency and sleep duration from the PSQI were compared by ANCOVA (controlling for age) between the MT, NT and ET groups overall and in the subset of males and females. The scores of the three components of the PSQI (subjective sleep quality, sleep disturbance, and use of sleep medication) were also compared by the same type of analysis. Statistical significance was defined as a $\mathrm{p}$ value below 0.05 . When significant differences were found between ME types, post-hoc tests were conducted to determine which of the three groups were different.

\section{RESULTS}

The population was middle-aged, and the men were significantly older than the women, although the average age difference was less than 4 years (Table 1). The population on average 
was well-educated, with the men having a small ( 0.5 years) but statistically significantly greater duration of education. The average score of the MEQ-K after controlling for age by ANCOVA was higher in the men than in the women indicating greater morningness tendency, although the average MEQ-K score for both genders was in the neither type range. While the average KESS score of the men was significantly higher than that of the women, the average KESS scores of both groups indicated only moderate levels of daytime sleepiness. There was no significant difference in the PSQI score between the men and women, and on average, both groups fell within the good sleeper range (Table 1). On the PSQI, the women reported slightly but significantly earlier bedtimes, significantly longer self-reported sleep latencies, greater sleep disturbance, and less caffeine usage (Table 2).

When we examined the group data separated by ME type, we found that the average score on the PSQI in the ET subjects was significantly higher than that of the MT or NT subjects overall, as well as within the subsets of men and women (Table $3)$. Among the entire group, as well as in the subsets of men and women, the bedtime and wake time of ET subjects were significantly later compared to those of MT or NT subjects, as ex- pected (Table 4). Among the entire group as well as among the subsets of men and women, the ET subjects reported higher subjective sleep quality component scores from the PSQI (Table 4 ), indicating poorer quality sleep. In the entire group, ET subjects also reported significantly longer subjective sleep latencies than NT or ET subjects, but among the subsets of men and women, while the ET did on average report longer subjective sleep latencies, this was not statistically significant (Table 4).

In the overall group, results from the PSQI indicated a significantly shorter sleep duration and greater caffeine consumption in ET subjects when compared to those of MT or NT subjects (Table 4). This was also found in the group of women, but not in the group of men (Fig. 1).

Daytime sleepiness as reported on the KESS was significantly greater in the ET than the NT or MT overall and among the women, but did not reach significance among the men (Table 3, Fig. 1).

\section{DISCUSSION}

In our study, the MEQ-K scores in the male group were

Table 1. Demographic features and scores on MEQ-K, KESS and PSQI in male and female subjects

\begin{tabular}{|c|c|c|c|c|c|}
\hline & $\begin{array}{c}\text { Male } \\
(\mathrm{n}=346)\end{array}$ & $\begin{array}{c}\text { Female } \\
(\mathrm{n}=565)\end{array}$ & $\begin{array}{c}\text { Overall } \\
(\mathrm{n}=911)\end{array}$ & \multirow[t]{2}{*}{$\mathrm{F}$} & \multirow[t]{2}{*}{$\mathrm{p}$} \\
\hline & \multicolumn{3}{|c|}{ Mean (SD) } & & \\
\hline Age (y) & $40.58(11.89)^{* *}$ & $36.98(10.10)$ & $38.35(10.95)$ & 23.775 & $<0.0001$ \\
\hline Education (y) & $15.08(2.94)^{*}$ & $14.58(2.88)$ & $14.77(2.91)$ & 6.178 & 0.013 \\
\hline MEQ-K ${ }^{\dagger}$ & $52.64(8.62)^{* *}$ & $50.62(8.50)$ & $51.39(8.60)$ & 91.50 & $<0.0001$ \\
\hline $\mathrm{KESS}^{\dagger}$ & $8.64(3.82)^{*}$ & $8.04(3.44)$ & $8.27(3.60)$ & 3.927 & 0.020 \\
\hline $\mathrm{PSQI}^{\dagger}$ & $4.68(2.33)$ & $5.04(2.82)$ & $4.91(2.65)$ & 1.851 & 0.158 \\
\hline
\end{tabular}

${ }^{*} \mathrm{p}<0.05,{ }^{* *} \mathrm{p}<0.0001$ (ANOVA, ${ }^{\dagger}$ ANCOVA controlling for age).

MEQ-K: Korean version of Morningness-Eveningness Questionnaire, KESS: Korean version of Epworth Sleepiness Scale, PSQI: Pittsburgh Sleep Quality Index.

Table 2. Subjective sleep variables from the PSQI in male and female subjects

\begin{tabular}{|c|c|c|c|c|c|}
\hline & $\begin{array}{c}\text { Male } \\
(\mathrm{n}=327)\end{array}$ & $\begin{array}{c}\text { Female } \\
(\mathrm{n}=540)\end{array}$ & $\begin{array}{c}\text { Overall } \\
(n=911)\end{array}$ & \multirow[t]{2}{*}{$\mathrm{F}$} & \multirow[t]{2}{*}{$\mathrm{p}$} \\
\hline & \multicolumn{3}{|c|}{ Mean (SD) } & & \\
\hline Bed time $(\mathrm{h}: \mathrm{m})$ & $23: 44(1.16)$ & $23: 40(1.19)^{*}$ & $23: 42(1.19)$ & 6.377 & 0.012 \\
\hline Wake time $(\mathrm{h}: \mathrm{m})$ & $06: 50(1.04)$ & $07: 00(1.07)$ & $06: 55(1.06)$ & 0.082 & 0.774 \\
\hline Sleep latency (min) & $16.73(15.64)$ & $20.71(17.82)^{*}$ & $19.53(17.30)$ & 6.310 & 0.012 \\
\hline Subjective sleep quality ${ }^{\dagger}$ & $0.95(0.73)$ & $1.06(0.78)$ & $1.03(0.76)$ & 1.192 & 0.275 \\
\hline Sleep disturbance ${ }^{\dagger}$ & $0.87(0.45)$ & $0.96(0.48)^{*}$ & $0.92(0.47)$ & 5.519 & 0.019 \\
\hline Use of sleep medication $^{\dagger}$ & $0.05(0.30)$ & $0.01(0.14)$ & $0.03(0.21)$ & 2.055 & 0.152 \\
\hline Sleep duration (min) & $6.68(1.26)$ & $6.84(1.25)$ & $6.79(1.18)$ & 2.472 & 0.116 \\
\hline Caffeine amount (cup) & $2.61(1.75)$ & $2.23(1.26)^{* *}$ & $2.37(1.49)$ & 8.447 & 0.004 \\
\hline
\end{tabular}

${ }^{*} \mathrm{p}<0.05,{ }^{* *} \mathrm{p}<0.01$ (ANCOVA controlling for age). ${ }^{\dagger}$ Component score of PSQI.

PSQI: Pittsburgh Sleep Quality Index. 
Table 3. MEQ-K and PSQI scores in the MT, NT and ET groups

\begin{tabular}{|c|c|c|c|c|c|c|}
\hline & \multicolumn{3}{|c|}{ ME-type } & \multirow{3}{*}{$\mathrm{F}$} & \multirow{3}{*}{$\mathrm{p}$} & \multirow{3}{*}{ Bonferroni } \\
\hline & MT & NT & ET & & & \\
\hline & \multicolumn{3}{|c|}{ Mean (SD) } & & & \\
\hline Total subjects $(\mathrm{n}=911)$ & $(\mathrm{n}=189)$ & $(\mathrm{n}=615)$ & $(\mathrm{n}=107)$ & & & \\
\hline MEQ-K & $63.48(4.42)$ & $50.08(4.61)$ & $37.54(3.42)^{* *}$ & 1046.95 & $<0.0001$ & $\mathrm{M}>\mathrm{N}>\mathrm{E}$ \\
\hline KESS & $7.62(3.84)$ & $8.38(3.50)$ & $8.71(3.59)^{*}$ & 3.56 & 0.029 & $\mathrm{M}<\mathrm{N}=\mathrm{E}$ \\
\hline PSQI & $4.63(2.99)$ & $4.81(2.47)$ & $5.92(2.81)^{* *}$ & 9.49 & 0.001 & $\mathrm{M}=\mathrm{N}<\mathrm{E}$ \\
\hline Male subjects $(\mathrm{n}=346)$ & $(\mathrm{n}=94)$ & $(\mathrm{n}=218)$ & $(\mathrm{n}=34)$ & & & \\
\hline MEQ-K & $62.72(0.46)$ & $50.43(0.29)$ & $38.91(0.74)^{* *}$ & 412.66 & $<0.0001$ & $\mathrm{M}>\mathrm{N}>\mathrm{E}$ \\
\hline KESS & $8.25(0.41)$ & $8.85(0.26)$ & $8.35(0.67)$ & 0.86 & 0.424 & $\mathrm{M}<\mathrm{N}=\mathrm{E}$ \\
\hline PSQI & $4.15(0.26)$ & $4.78(0.16)$ & $5.49(0.41)^{*}$ & 3.85 & 0.022 & $\mathrm{M}=\mathrm{N}, \mathrm{N}=\mathrm{E}, \mathrm{M}<\mathrm{E}$ \\
\hline Female subjects $(\mathrm{n}=565)$ & $(\mathrm{n}=95)$ & $(\mathrm{n}=397)$ & $(\mathrm{n}=73)$ & & & \\
\hline MEQ-K & $62.88(0.47)$ & $50.04(0.22)$ & $37.69(0.52)^{* *}$ & 630.60 & $<0.0001$ & $\mathrm{M}>\mathrm{N}>\mathrm{E}$ \\
\hline KESS & $7.09(0.37)$ & $8.11(0.17)$ & $8.80(0.40)^{* *}$ & 5.00 & 0.007 & $\mathrm{M}<\mathrm{N}=\mathrm{E}$ \\
\hline PSQI & $4.98(0.31)$ & $4.84(0.14)$ & $6.19(0.33)^{* *}$ & 6.92 & 0.001 & $\mathrm{M}=\mathrm{N}<\mathrm{E}$ \\
\hline
\end{tabular}

${ }^{*} \mathrm{p}<0.05,{ }^{* *} \mathrm{p}<0.01$ (ANCOVA controlling for age).

ME: morningness-eveningness, MT: morning type, NT: neither type, ET: evening type, MEQ-K: Korean version of Morningness-Eveningness Questionnaire, KESS: Korean version of Epworth Sleepiness Scale, PSQI: Pittsburgh Sleep Quality Index.

slightly but significantly higher than those of the female group, even when controlling for age. This indicates that this group of men had a greater tendency toward morningness than the women, although the average scores for both groups fell within the NT range. Previous studies have shown contradictory results on whether there is a gender difference in ME preference. ${ }^{8,14,21} \mathrm{~A}$ study on the general population in Italy suggested that male subjects had a greater tendency toward eveningness compared to female subjects, because the male subjects had later mid sleep timings than those of female subjects. ${ }^{17}$ On the other hand, a study from Finland reported a possible tendency toward morningness among men, due to a greater proportion of MT among the male subjects. ${ }^{14}$ However, large studies among general populations have emphasized the potentially greater importance of age and work schedules in determining the individual ME type. ${ }^{8,9}$ According to such studies, factors other than gender may play a more important role in determining the ME type, although there are reports of gender differences in physiological circadian rhythms. ${ }^{11}$ On average, the subjects in the current study were of working age (mean age 38.35 years), suggesting that the influence of work schedule (and gender differences in work schedules) may have contributed to our findings, although we did not collect information about employment status or work hours. Therefore, a further study on the relationship between employment status, work times, and ME preference and potential gender differences in those relationships should be conducted.

Sleep-wake behavior is one of the most robust presentations of circadian behavior among various behavioral phenomena. ${ }^{3,10}$ As expected, the mean bedtime and wake time of the ET group were later than those of the MT and NT groups overall and in both male and female subsets (Table 4). In previous studies, ET subjects were reported to show about a two hour difference in the bedtime and wake time compared to MT subjects, and this was most obvious on free days. ${ }^{2,21}$

In our study, ET subjects reported poorer sleep quality than MT or NT subjects regardless of gender (Table 4). Also, their sleep latency was longer than MT or NT subjects, although this only reached statistical significance among the overall group and not within the gender subgroups. Previous reports from self questionnaires have consistently found that ET subjects report worse sleep quality than MT subjects. ${ }^{2,7,22}$ Chung et al. ${ }^{7}$ surveyed factors that affect sleep quality in nurses working shifts, and reported that their degree of eveningness predicted poor sleep quality better than other factors including shift work or daily habits. Lehnkering et al. ${ }^{23}$ found decreased sleep efficiency among ET subjects when measured by actigraphy, suggesting a basis for their self-reported poor sleep quality. One possible cause of poor sleep quality among ET individuals is the temporal misalignment between the endogenous circadian rhythm of sleep propensity and the time at which ET individuals are attempting to sleep. This misalignment of sleep occurs in ET subjects due to social demands of work and school, which not only impacts sleep quality but also sleep duration on work or school nights. In fact, it was reported that adolescents with ET have a great difficulty in adapting to early school starting times. ${ }^{2}$ The poorer subjective sleep quality in ET individuals in our study may therefore result from both difficulty waking up as well as difficulty initiating sleep ${ }^{4}$ as evidenced by the longer sleep latencies reported in our ET subjects. 
Table 4. Subjective sleep variables from the PSQI in the MT, NT and ET groups

\begin{tabular}{|c|c|c|c|c|c|c|}
\hline & \multicolumn{3}{|c|}{ ME-type } & \multirow{3}{*}{$\mathrm{F}$} & \multirow{3}{*}{$\mathrm{p}$} & \multirow{3}{*}{ Bonferroni } \\
\hline & MT & NT & ET & & & \\
\hline \multicolumn{4}{|c|}{ Mean (SD) } & & & \\
\hline Total subjects $(\mathrm{n}=911)$ & $(\mathrm{n}=189)$ & $(\mathrm{n}=615)$ & $(\mathrm{n}=107)$ & & & \\
\hline Bedtime & $22.80(0.95)$ & $23.80(1.07)$ & $24.6(1.19)^{* *}$ & 75.93 & $<0.0001$ & $\mathrm{M}<\mathrm{N}<\mathrm{E}$ \\
\hline Wake time & $6.21(0.87)$ & $7.03(0.96)$ & $7.67(1.23)^{* *}$ & 45.13 & $<0.0001$ & $\mathrm{M}<\mathrm{N}<\mathrm{E}$ \\
\hline Sleep latency (min) & $18.39(17.76)$ & $19.13(16.70)$ & $23.82(19.34)^{*}$ & 4.03 & 0.018 & $\mathrm{M}=\mathrm{N}<\mathrm{E}$ \\
\hline Subjective sleep quality ${ }^{\dagger}$ & $0.88(0.72)$ & $1.02(0.73)$ & $1.36(0.88)^{* *}$ & 11.38 & $<0.0001$ & $\mathrm{M}=\mathrm{N}<\mathrm{E}$ \\
\hline Sleep disturbance ${ }^{\dagger}$ & $0.90(0.49)$ & $0.92(0.47)$ & $0.97(0.42)$ & 0.87 & 0.418 & $\mathrm{M}=\mathrm{N}=\mathrm{E}$ \\
\hline Use of sleep medication $^{\dagger}$ & $0.02(0.18)$ & $0.03(0.22)$ & $0.03(0.22)$ & 0.52 & 0.597 & $\mathrm{M}=\mathrm{N}=\mathrm{E}$ \\
\hline Sleep duration (min) & $6.83(1.15)$ & $6.81(1.17)$ & $6.56(1.28)^{*}$ & 3.46 & 0.032 & $\mathrm{M}=\mathrm{N}>\mathrm{E}$ \\
\hline Caffeine amount (cup) & $2.23(1.09)$ & $2.40(1.59)$ & $2.44(1.47)$ & 3.18 & 0.042 & $\mathrm{M}=\mathrm{N}=\mathrm{E}$ \\
\hline Male subjects $(\mathrm{n}=346)$ & $(\mathrm{n}=94)$ & $(\mathrm{n}=218)$ & $(\mathrm{n}=34)$ & & & \\
\hline Bedtime (h:m) & $23: 10(0.10)$ & $23: 49(0.07)$ & $00: 41(0.17)^{*}$ & 30.19 & $<0.0001$ & $\mathrm{M}<\mathrm{N}<\mathrm{E}$ \\
\hline Wake time $(\mathrm{h}: \mathrm{m})$ & $06: 15(0.09)$ & $06: 54(0.06)$ & $07: 57(0.15)^{*}$ & 43.10 & $<0.0001$ & $\mathrm{M}<\mathrm{N}<\mathrm{E}$ \\
\hline Sleep latency (min) & $14.91(1.75)$ & $17.44(1.10)$ & $22.28(2.87)$ & 2.29 & 0.102 & $\mathrm{M}=\mathrm{N}=\mathrm{E}$ \\
\hline Subjective sleep quality ${ }^{\dagger}$ & $0.70(0.08)$ & $1.01(0.05)$ & $1.44(0.13)^{*}$ & 12.13 & $<0.0001$ & $\mathrm{M}<\mathrm{N}<\mathrm{E}$ \\
\hline Sleep disturbance ${ }^{\dagger}$ & $0.81(0.05)$ & $0.88(0.03)$ & $0.99(0.08)$ & 1.90 & 0.151 & $\mathrm{M}=\mathrm{N}=\mathrm{E}$ \\
\hline Use of sleep medication $^{\dagger}$ & $0.01(0.03)$ & $0.06(0.02)$ & $0.07(0.05)$ & 1.17 & 0.313 & $\mathrm{M}=\mathrm{N}=\mathrm{E}$ \\
\hline Sleep duration (min) & $6.72(0.11)$ & $6.65(0.07)$ & $6.89(0.18)$ & 0.86 & 0.424 & $\mathrm{M}=\mathrm{N}=\mathrm{E}$ \\
\hline Caffeine amount (cup) & $2.33(0.20)$ & $2.75(0.13)$ & $2.52(0.33)$ & 1.61 & 0.201 & $\mathrm{M}=\mathrm{N}=\mathrm{E}$ \\
\hline Female subjects $(\mathrm{n}=565)$ & $(\mathrm{n}=95)$ & $(\mathrm{n}=397)$ & $(\mathrm{n}=73)$ & & & \\
\hline Bedtime (h:m) & $22: 47(0.11)$ & $23: 45(0.05)$ & $00: 30(0.13)^{* *}$ & 50.23 & $<0.0001$ & $\mathrm{M}<\mathrm{N}<\mathrm{E}$ \\
\hline Wake time $(\mathrm{h}: \mathrm{m})$ & $06: 31(0.10)$ & $07: 03(0.05)$ & $07: 19(0.11)^{* *}$ & 14.94 & $<0.0001$ & $\mathrm{M}<\mathrm{N}=\mathrm{E}$ \\
\hline Sleep latency (min) & $20.91(1.90)$ & $20.17(0.90)$ & $24.96(2.13)$ & 2.17 & 0.115 & $\mathrm{M}=\mathrm{N}=\mathrm{E}$ \\
\hline Subjective sleep quality ${ }^{\dagger}$ & $1.06(0.083)$ & $1.02(0.04)$ & $1.31(0.09)^{*}$ & 4.11 & 0.017 & $\mathrm{M}=\mathrm{N}<\mathrm{E}$ \\
\hline Sleep disturbance ${ }^{\dagger}$ & $0.97(0.05)$ & $0.95(0.03)$ & $0.97(0.06)$ & 0.09 & 0.911 & $\mathrm{M}=\mathrm{N}=\mathrm{E}$ \\
\hline Use of sleep medication $^{\dagger}$ & $0.03(0.02)$ & $0.01(0.01)$ & $0.02(0.02)$ & 0.27 & 0.764 & $\mathrm{M}=\mathrm{N}=\mathrm{E}$ \\
\hline Sleep duration (min) & $7.04(0.14)$ & $6.89(0.06)$ & $6.36(0.15)^{* *}$ & 6.38 & 0.002 & $\mathrm{M}=\mathrm{N}>\mathrm{E}$ \\
\hline Caffeine amount (cup) & $1.91(0.15)$ & $2.22(0.07)$ & $2.52(0.15)^{*}$ & 3.86 & 0.022 & $\mathrm{M}=\mathrm{N}<\mathrm{E}$ \\
\hline
\end{tabular}

${ }^{*} \mathrm{p}<0.05,{ }^{* *} \mathrm{p}<0.01$ (ANCOVA controlling for age). ${ }^{\dagger}$ Component score of PSQI.

ME: morningness-eveningness, MT: morning type, NT: neither type, ET: evening type, PSQI: Pittsburgh Sleep Quality Index.

Several previous studies have shown that the sleep duration of ET subjects is shorter when compared to MT or NT subjects. ${ }^{2,3,9,10,14,24}$ Consistent with several previous reports, our study found a significantly shorter reported sleep duration overall in ET subjects than in NT or MT subjects, and shorter reported sleep duration among the female ET subjects, but not in the males (Fig. 1A). In a previous study among the general population, the experience of insufficient sleep was reported to be more prevalent among ET than MT, and to be associated with shorter sleep duration. ${ }^{14}$ Taillard et al. ${ }^{4}$ found that ET more frequently varied their bedtime and arising time by more than $2 \mathrm{~h}$ than other chronotypes, and suggested that their irregular sleep wake schedules were related to their shorter sleep duration. In another previous study, ET subjects reported a signifi- cantly greater need for sleep than MT, but slept significantly less than during working days. ${ }^{2}$ An alternative explanation of the reports of greater sleep need among ET compared to MT is that ET subjects are unable to obtain sufficient sleep during weekdays and attempt to make up for this sleep deficit on weekends. ${ }^{28}$

In our study, the daytime sleepiness of ET women was greater and their caffeine consumption amount was also greater compared to MT or NT women. Although previous studies in adolescents have reported that daytime sleepiness is greater in ET individuals, ${ }^{2,26}$ not all studies in adults have found a significant difference in daytime sleepiness related to ME type. ${ }^{4,27,28}$ ET individuals may have greater daytime sleepiness due to a number of factors, including poor sleep quality and shorter sleep dura- 

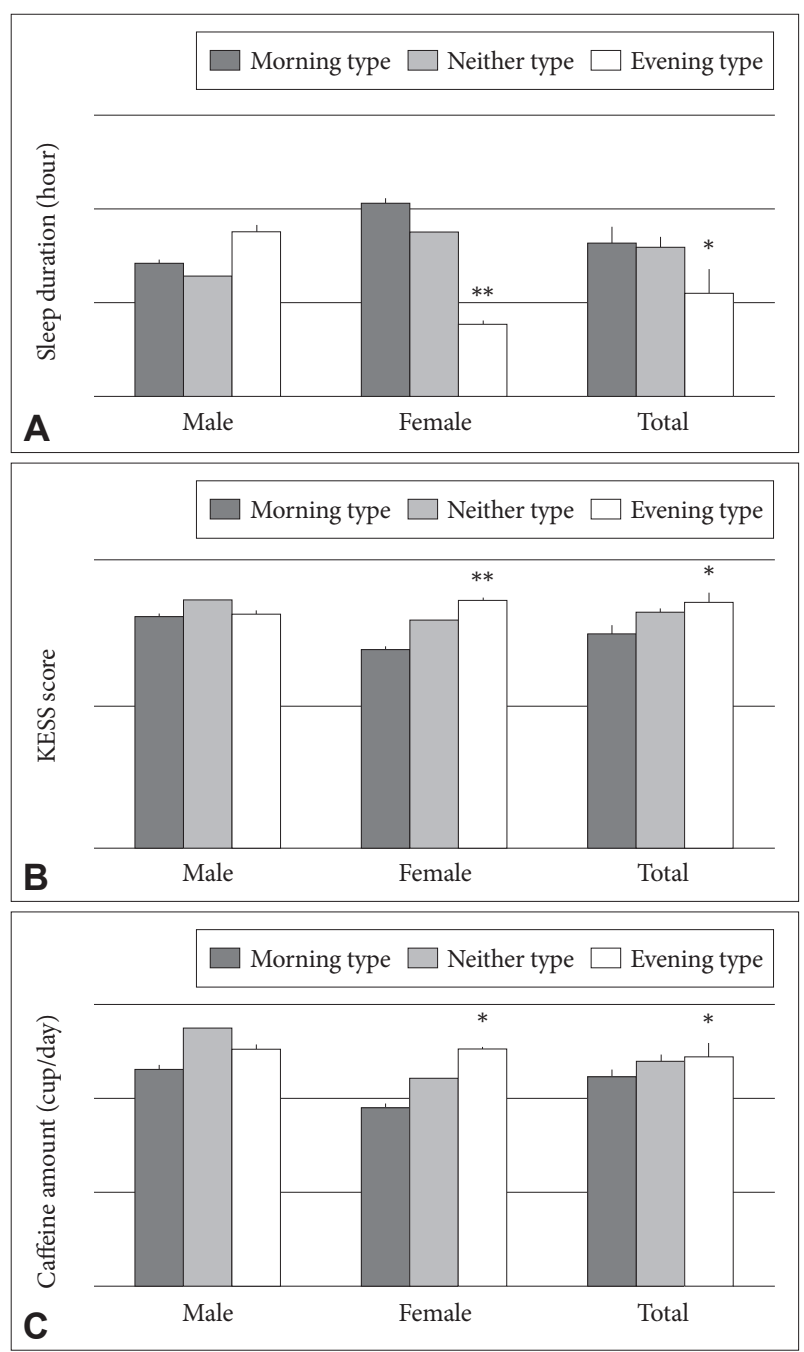

Fig. 1. Differences in sleep duration (hour) (A), KESS score (B), and caffeine amount (cup/day) (C) by the ME types in male and female subjects. Data presented as mean \pm SE. ${ }^{*} p<0.05,{ }^{* *} p<$ 0.01 (ANCOVA controlling for age). KESS: Korean version of Epworth Sleepiness Scale, ME: morningness-eveningness.

tion related to the mismatch between their rhythms of sleep propensity and their selected sleep times, and irregular sleep timing (particularly between weekdays and weekends). ${ }^{24}$ Soehner et al. ${ }^{3}$ reported that daytime workers with ET had irregular sleep habits, which was associated with reduced sleep duration and increased daytime sleepiness. This suggests that greater daytime sleepiness among ET individuals is secondary to their reduced sleep duration. In one prior study, ET subjects with daytime sleepiness complaints increased their caffeine intake. ${ }^{2}$ This is consistent with our finding that the ET women in our study, who had the shortest sleep durations and the greatest daytime sleepiness, also had the largest reported caffeine consumption. ${ }^{4}$

Our study has several limitations which reduce our ability to interpret our findings. First, we did not collect information about occupation or working hours, or home and family responsibilities, limiting our ability to examine the occupational and social factors which may affect sleep timing and duration and/or ME preference. Additional studies where information about employment status, family responsibilities, and other factors that may contribute to ME preference are collected should therefore be conducted to examine whether such factors contribute to the observed gender differences in our study. We conducted our study only on weekends and during the afternoon hours (between 1:00 PM and 5:00 PM), and our sample population may therefore have been biased by the location and/or timing of data collection. Additional data collection throughout the week and in the early morning or evening could address this limitation. Furthermore, our study was questionnaire-based and did not include an objective assessment of sleep or daytime sleepiness, somewhat limiting our findings. We also did not ask about major psychiatric disorders or medical diseases that might affect sleep, and therefore, the potential inclusion of such individuals may have influenced our findings.

In conclusion, our study found that ET subjects perceived their sleep quality as poorer than that of MT or NT subjects, regardless of gender. We also found that ET women had significantly shorter sleep duration, greater daytime sleepiness, and larger caffeine consumption than MT or NT women, and there were similar trends among the men.

\section{Acknowledgments}

Basic Science Research Program through the National Research Foundation of Korea (NRF) funded by the Ministry of Education, Science and Technology (2010-0003160 to JHL). JFD supported by NIH grants HL080978 and HL077453, and by the Brigham and Women's Hospital BRI Fund to Sustain Research Excellence.

This paper was presented at the 2011 Annual Meeting of the Associated Professional Sleep Societies in Minneapolis, United States.

\section{Conflicts of Interest}

The authors have no financial conflicts of interest.

\section{REFERENCES}

1. Smith CS, Reilly C, Midkiff K. Evaluation of three circadian rhythm questionnaires with suggestions for an improved measure of morningness. J Appl Psychol 1989;74:728-38.

2. Giannotti F, Cortesi F, Sebastiani T, Ottaviano S. Circadian preference, sleep and daytime behaviour in adolescence. J Sleep Res 2002;11:191-9.

3. Soehner AM, Kennedy KS, Monk TH. Circadian preference and sleepwake regularity: associations with self-report sleep parameters in daytime-working adults. Chronobiol Int 2011;28:802-9.

4. Taillard J, Philip P, Bioulac B. Morningness/eveningness and the need for sleep. J Sleep Res 1999;8:291-5.

5. Ishihara K, Miyake S, Miyasita A, Miyata Y. Comparisons of sleep-wake habits of morning and evening types in Japanese worker sample. J Hum Ergol (Tokyo) 1988;17:111-8.

6. Akerstedt T, Kecklund G, Selén J. Early morning work--prevalence and relation to sleep/wake problems: a national representative survey. Chronobiol Int 2010;27:975-86.

7. Chung MH, Chang FM, Yang CC, Kuo TB, Hsu N. Sleep quality and morningness-eveningness of shift nurses. J Clin Nurs 2009;18:279-84.

8. Adan A, Almirall H. Adaptation and standardization of a spanish version of the morningness-eveningness questionnaire: individual differences. Personal Individ Differ 1990;11:1123-30. 
9. Paine SJ, Gander PH, Travier N. The epidemiology of morningness/ eveningness: influence of age, gender, ethnicity, and socioeconomic factors in adults (30-49 years). J Biol Rhythms 2006;21:68-76.

10. Roenneberg T, Kuehnle T, Juda M, Kantermann T, Allebrandt K, Gordijn M, et al. Epidemiology of the human circadian clock. Sleep Med Rev 2007;11:429-38.

11. Duffy JF, Cain SW, Chang AM, Phillips AJ, Münch MY, Gronfier C, et al. Sex difference in the near-24-hour intrinsic period of the human circadian timing system. Proc Natl Acad Sci U S A 2011;108 Suppl 3:15602-8.

12. Bae SM, Park JE, Lee YJ, Cho IH, Kim JH, Koh SH, et al. Gender difference in the association between adult attention deficit hyperactivity disorder symptoms and morningness-eveningness. Psychiatry Clin Neurosci 2010;64:649-51.

13. Killgore WD, Killgore DB. Morningness-eveningness correlates with verbal ability in women but not men. Percept Mot Skills 2007;104:335-8.

14. Merikanto I, Kronholm E, Peltonen M, Laatikainen T, Lahti T, Partonen T. Relation of chronotype to sleep complaints in the general Finnish population. Chronobiol Int 2012;29:311-7.

15. Adan A, Natale V. Gender differences in morningness-eveningness preference. Chronobiol Int 2002;19:709-20.

16. Roenneberg T, Kuehnle T, Pramstaller PP, Ricken J, Havel M, Guth A, et al. A marker for the end of adolescence. Curr Biol 2004;14:R1038-9.

17. Tonetti L, Fabbri M, Natale V. Sex difference in sleep-time preference and sleep need: a cross-sectional survey among Italian pre-adolescents, adolescents, and adults. Chronobiol Int 2008;25:745-59.

18. Horne JA, Ostberg O. A self-assessment questionnaire to determine morningness-eveningness in human circadian rhythms. Int J Chronobiol 1976;4:97-110.

19. Cho YW, Lee JH, Son HK, Lee SH, Shin C, Johns MW. The reliability and validity of the Korean version of the Epworth sleepiness scale. Sleep Breath 2011;15:377-84.

20. Buysse DJ, Reynolds CF 3rd, Monk TH, Berman SR, Kupfer DJ. The Pittsburgh Sleep Quality Index: a new instrument for psychiatric practice and research. Psychiatry Res 1989;28:193-213.

21. Mongrain V, Lavoie S, Selmaoui B, Paquet J, Dumont M. Phase relationships between sleep-wake cycle and underlying circadian rhythms in Morningness-Eveningness. J Biol Rhythms 2004;19:248-57.

22. Megdal SP, Schernhammer ES. Correlates for poor sleepers in a Los Angeles high school. Sleep Med 2007;9:60-3.

23. Lehnkering H, Siegmund R. Influence of chronotype, season, and sex of subject on sleep behavior of young adults. Chronobiol Int 2007;24: 875-88.

24. Manber R, Bootzin RR, Acebo C, Carskadon MA. The effects of regularizing sleep-wake schedules on daytime sleepiness. Sleep 1996;19:43241.

25. Kim S, Dueker GL, Hasher L, Goldstein D. Children's time of day preference: age, gender and ethnic differences. Personal Individ Differ 2002;33:1083-90.

26. Gaina A, Sekine M, Kanayama H, Takashi Y, Hu L, Sengoku K, et al. Morning-evening preference: sleep pattern spectrum and lifestyle habits among Japanese junior high school pupils. Chronobiol Int 2006;23: 607-21.

27. Rosenthal L, Day R, Gerhardstein R, Meixner R, Roth T, Guido P, et al. Sleepiness/alertness among healthy evening and morning type individuals. Sleep Med 2001;2:243-8.

28. Roepke SE, Duffy JF. Differential impact of chronotype on weekday and weekend sleep timing and duration. Nat Sci Sleep 2010;2010:213-20. 